\title{
Influence of Topical, Systemic and Combined Application of Antioxidants on the Barrier Properties of the Human Skin
}

\author{
Juergen Lademann ${ }^{a}$ Theognosia Vergou $^{b}$ Maxim E. Darvin ${ }^{a}$ \\ Alexa Patzelt ${ }^{a}$ Martina C. Meinke ${ }^{a}$ Christiane Voit ${ }^{a}$ Dimitrios Papakostas $^{a}$ \\ Leonhard Zastrow $^{\mathrm{a}} \quad$ Wolfram Sterry ${ }^{\mathrm{a}}$ Olivier Doucet ${ }^{\mathrm{c}}$ \\ ${ }^{a}$ Center of Experimental and Applied Cutaneous Physiology (CCP), Department of Dermatology, \\ Charité - Universitätsmedizin Berlin, Berlin, Germany; ' ${ }^{2}$ Department of Dermatology, Hospital 'A. Syggros', \\ University of Athens, Athens, Greece; ${ }^{\mathrm{C}}$ Coty Lancaster SAM, Monaco, Monaco
}

\section{Key Words}

Penetration · Skin barrier - Skin physiology · Antioxidants .

Free radicals $\cdot$ Epidermal thickness

\begin{abstract}
Background: The formation of free radicals in human skin by solar ultraviolet radiation is considered to be the main reason for extrinsic skin aging. The antioxidants in human tissue represent an efficient protection system against the destructive action of these reactive free radicals. In this study, the parameters of the skin, epidermal thickness, stratum corneum moisture, elasticity and wrinkle volume, were determined before and after the treatment with antioxidant- or placebo-containing tablets and creams. Methods: The study included 5 groups of 15 volunteers each, who were treated for 2 months with antioxidant-containing or placebo tablets, creams or a combination of antioxidant-containing tablets and cream. The skin parameters were measured at time point 0 and at week 8 utilizing ultrasound for the determination of epidermal thickness, a corneometer for stratum corneum moisture measurements, skin profilometry for quantifying the wrinkle volume and a cutometer for determining the elasticity. Results: The verum cream had a positive influ-
\end{abstract}

ence on epidermal thickness, elasticity and skin moisture, but the verum tablets improved the epidermal thickness only. The combined application of verum tablets and creams led to a significant improvement of all investigated skin parameters, whereas the application of placebo tablets or cream did not influence any parameters. Conclusion: The topical and oral supplementation of antioxidants can be an instrument to improve several skin parameters and potentially counteract or decelerate the process of extrinsic skin aging.

(c) 2016 S. Karger AG, Basel

\section{Introduction}

The skin is not only the largest organ of the human body but also the barrier between the organism and the environment. It protects the human body from water loss, the penetration of harmful agents and solar UV radiation [1]. Solar radiation represents the factor most responsible for the formation of free radicals in human skin $[2,3]$. The spectral distribution of these free radicals has a maximum in the UV region [4]. These highly reactive molecules can destroy cells and cell compartments. The

Dr. med. Alexa Patzel

Center of Experimental and Applied Cutaneous Physiology

Department of Dermatology

Charité - Universitätsmedizin Berlin, Charitéplatz 1, DE-10117 Berlin (Germany)

E-Mail alexa.patzelt@ charite.de 
Table 1. Initial values of the skin parameters of all groups

\begin{tabular}{lllllc}
\hline Cream group & - & - & $\mathrm{AO}$ & $\mathrm{AO}$ & $\mathrm{P}$ \\
\hline Tablet group & $\mathrm{AO}$ & $\mathrm{P}$ & $\mathrm{AO}$ & - & - \\
\hline Gender & female & female & female & female & female \\
Age, years & $38 \pm 8$ & $27.4 \pm 3$ & $31.5 \pm 8$ & $36.7 \pm 9$ & $35.3 \pm 10$ \\
Skin moisture, arbitrary units & $81 \pm 2$ & $81.5 \pm 50$ & $72.5 \pm 7$ & $75.5 \pm 6$ & $84.7 \pm 10$ \\
Wrinkle volume, $\mathrm{mm}^{3}$ & $0.9 \pm 0.6$ & $0.5 \pm 0.1$ & $0.8 \pm 0.2$ & $1 \pm 0.3$ & $0.6 \pm 0.5$ \\
Epidermal thickness, $\mu \mathrm{m}$ & $85.1 \pm 9$ & $84.8 \pm 10$ & $81 \pm 9$ & $82.6 \pm 11$ & $88.7 \pm 8$ \\
Skin elasticity, arbitrary units & $0.5 \pm 0.2$ & $0.5 \pm 0.1$ & $0.6 \pm 0.1$ & $0.6 \pm 0.1$ & $0.5 \pm 0.1$ \\
\hline
\end{tabular}

Values are expressed as means $\pm \mathrm{SD}$.

radicals and reactive oxygen species (ROS) not only damage DNA but also negatively influence the generation of connective tissue $[5,6]$. UV irradiation induces matrix metalloproteinases that are responsible for alterations in the collagenous extracellular matrix of connective tissue [7]. These alterations result in an impaired integrity [8]. Skin aging, immunosuppression and also skin cancer can be the consequences of all these processes [9-11]. The human organism has developed a protection system against the destructive action of the free radicals in the form of antioxidants $[12,13]$. The antioxidants in human tissue are able to neutralize free radicals before they are in a position to damage the tissue. The most important antioxidants in human skin are carotenoids, vitamins and various enzymes $[14,15]$. However, most of these substances cannot be produced by the human organism but must be supplemented by nutrition such as fruits and vegetables. Thus, the antioxidant status of every human subject crucially depends on his specific nutrition. Interestingly, carotenoids have been shown to serve as marker substances for the complete antioxidant status of the human epidermis [16]. A correlation of the antioxidant status and the skin status has been shown previously. Darvin et al. [17] demonstrated that individuals who maintained a healthy diet over decades had a younger-looking skin with less furrows and wrinkles than persons of the same age with lower antioxidant levels in their skin. An accumulation of topically and systemically applied antioxidants in the human skin has been demonstrated in several studies [1820].

The aim of this study was to assess the influence of systemic, topical and combined applications of antioxidants on the skin barrier by examining 4 parameters (epidermal thickness, stratum corneum moisture, elasticity and wrinkle volume) over a period of 8 weeks.

\section{Materials and Methods}

\section{Volunteers}

In total, the investigations were performed on 75 female volunteers aged between 20 and 73 years with skin types II and III according to the Fitzpatrick classification [21]. Only volunteers with healthy skin conditions and without any known sensibilization to cosmetic products were included in the study. The study included 5 groups of 15 volunteers each, treated for 2 months with antioxidant-containing or placebo tablets, creams or a combination of antioxidant-containing tablets and cream. The skin parameters were measured at time point 0 and at week 8 . The mean initial values of the skin parameters of all groups are presented in table 1.

The study was approved by the Ethics Committee of the Charité - Universitätsmedizin Berlin and was conducted in accordance with the standard ethical rules stated in the principles of the Declaration of Helsinki.

\section{Applied Substances}

The active substrate in the verum cream and tablets comprised a basic compound of antioxidants including active ingredients such as vitamin $\mathrm{E}$ acetate, plant-derived vitamin $\mathrm{C}$ acetate, plant extracts (green tea, green coffee, pongamia, pinnata seed and angelica) and $0.2 \%$ of the carotenoids $\beta$-carotene and lycopene at the same concentrations. The placebo cream and tablets did not contain any antioxidants. The cream basis was a soft water-in-oil emulsion containing the following ingredients: isopropyl myristate, aramol E, veegum, xanthem gum, carbopol, cycomethicon and shea butter. The placebo tablets were composed of an inert tablet carrier. The antioxidant-containing cream and tablets are a proprietary composition of Coty Lancaster SAM as specified and published in Patent EP 1877095 ('Verwendung von freien Radikalfängern zum Schutz und Behandlung von durch Chemotherapie verursachten Haut- und Haarschäden' dated May 27, 2009).

\section{Study Design}

The study design was double-blind. Each group of 15 volunteers was either treated with antioxidant-containing tablets (tablet-AO), placebo tablets (tablet-P), antioxidant-containing cream (cream-AO), placebo cream (cream-P) or a combination of antioxidant-containing tablets and cream (tablet-AO + cream-AO). During the study, the creams were applied to the face and the tablets were administered orally ( 1 tablet) twice daily. All study groups
Lademann et al. 


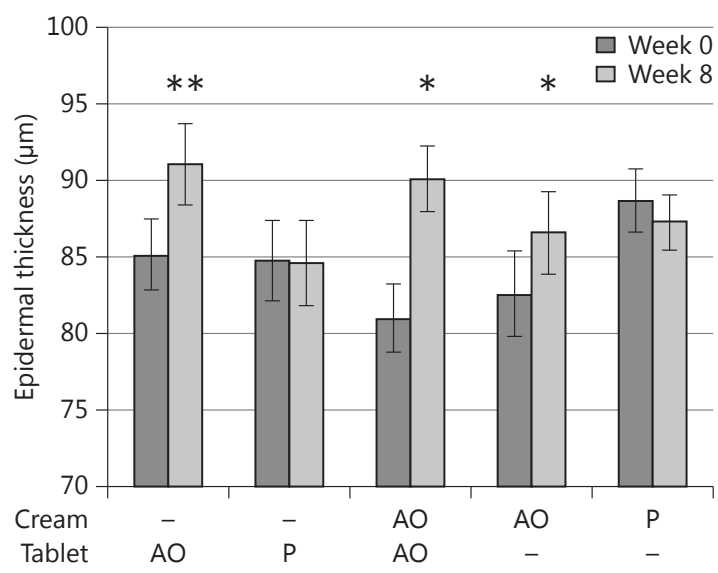

Fig. 1. Epidermal thickness of the human skin in vivo prior to and after 8 weeks of treatment. ${ }^{*} \mathrm{p}<0.05,{ }^{* *} \mathrm{p}<0.01$.

applied the respective test products for 8 weeks. The following parameters were determined at time point 0 and at week 8 .

\section{Epidermal Thickness}

The thickness of the epidermis was determined by ultrasound measurements. The measurements were performed using the 50 $\mathrm{MHz}$ system DermaScan ${ }^{\circledR}$ v3 (Cortex Technology, Denmark). Each skin area was measured 3 times and the mean value was determined. Absolute differences of approximately $3 \mu \mathrm{m}$ were regarded as changes.

\section{Classic Skin Parameters}

The wrinkle volume was measured using the PRIMOS premium (GFMesstechnik GmbH, Teltow, Germany). The elasticity measurements were performed by suction (Cutometer ${ }^{\circledR}$ dual MPA 580; Courage + Khazaka electronic GmbH, Köln, Germany). The parameter $\mathrm{R} 2$ showing the resistance versus the ability of returning was utilized for comparison. The stratum corneum moisture was measured by a capacitance method using the corneometer CM 825 (Courage + Khazaka electronic).

\section{Statistical Evaluation}

For statistical evaluation, mean values and standard deviations were calculated. The mean values were compared by means of the nonparametric Mann-Whitney U test and the Kruskal-Wallis test at a significance of $\mathrm{p}<0.05$, using the software program IBM SPSS Statistics 20.0.

\section{Results}

The results of the different skin parameters are shown in the figures. In figure 1, the epidermal thickness is shown prior to and after 8 weeks of treatment for all 5

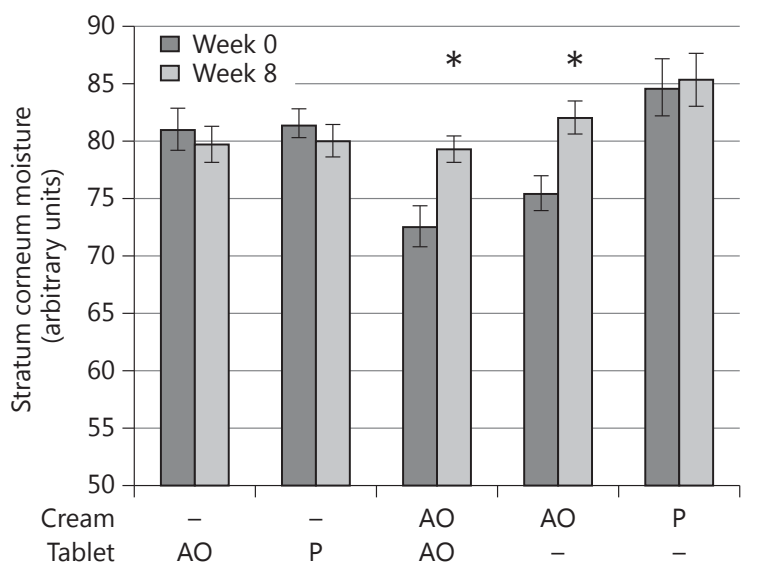

Fig. 2. Moisture in the stratum corneum prior to and after treatment. ${ }^{*} \mathrm{p}<0.05$.

groups. While placebo tablets and cream had no effect on the epidermal thickness, the application of antioxidants in the form of tablets and/or cream led to a significant increase in this parameter.

In figure 2 , the moisture in the stratum corneum is presented prior to and after 8 weeks of treatment for all 5 groups. Volunteers who received the cream-AO always showed an increase in stratum corneum moisture, but the stratum corneum moisture in the tablet- $\mathrm{AO}$ and tablet-P groups remained stable.

The effect of the different treatments on skin elasticity is shown in figure 3 . The elasticity of the skin was slightly but significantly improved in the cream-AO and tablet$\mathrm{AO}+$ cream-AO groups. In the case of systemic application of the antioxidants, only an insignificant increase in the elasticity could be observed after 8 weeks. Likewise, no effect was observed in the cream-P group.

The volume of the wrinkles changed significantly only in the tablet-AO + cream-AO group as shown in figure 4 .

\section{Discussion}

Free radicals produced in the human skin by solar radiation destroy cells and cell compartments [22, 23], collagen and elastin fibers and the lipid layers of the stratum corneum [24]. All this damages the skin barrier [25, 26]. Antioxidants in the skin can neutralize these reactive species $[27,28]$. Usually, these antioxidants must be supplemented by nutrition as they cannot be synthesized by the 


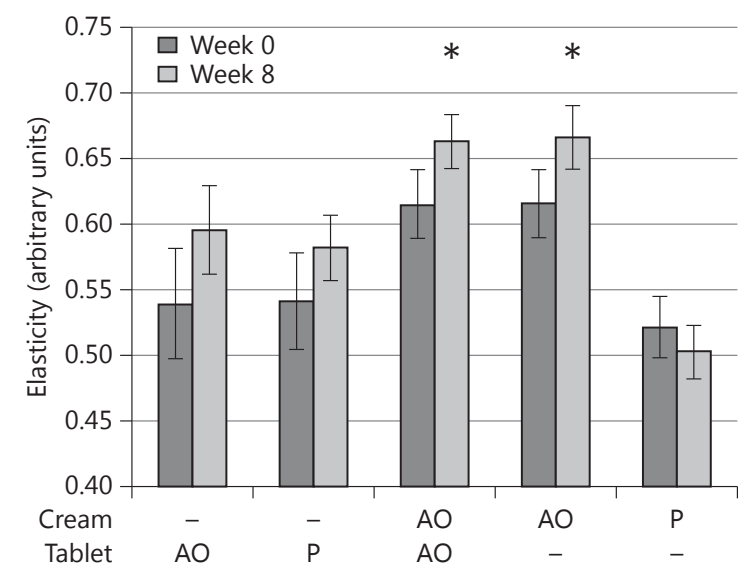

Fig. 3. Elasticity of the skin prior to and after 8 weeks of treatment. $* \mathrm{p}<0.05$.

organism itself. In this study, antioxidants were administered systemically in the form of tablets, topically in the form of a cream or as a combination of both over a period of 8 weeks. The verum cream had a positive influence on the epidermal thickness, elasticity and skin moisture; the verum tablets only improved the epidermal thickness. The combined application of verum tablets and creams led to a significant improvement of all skin parameters, whereas the application of placebo tablets or cream had no influence on any of the investigated skin parameters. This excludes that the observed effects were due to other ingredients of the creams or tablets.

Darvin et al. [29] showed that antioxidants administered in the form of tablets increased the antioxidant concentration in the skin. Their findings are the basis for explaining the results of our study. In the verum groups, the destructive action of the free radicals induced by solar radiation was reduced during the 8 weeks of investigation. UV exposure is thought to cause skin aging mainly by singlet oxygen-dependent pathways. This, in turn, leads to degradation, e.g. of the extracellular matrix proteins, by inducing matrix metalloproteases [30]. On the contrary, antioxidants such as $\beta$-carotene significantly reduce stress and degradation of the extracellular matrix, in addition to promoting the differentiation of keratinocytes [31], which might explain the improved skin parameters that we observed. Skin elasticity is particularly influenced by dermal collagen [32]. UV radiation, however, attacks keratinocytes and fibroblasts, resulting in

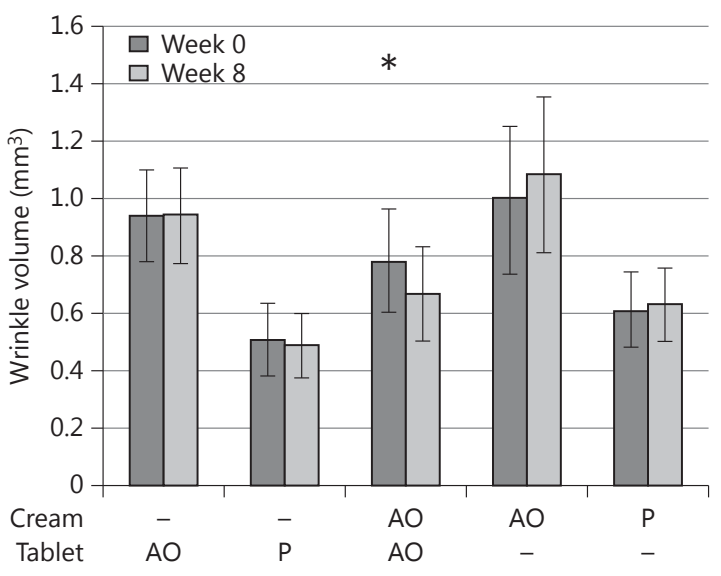

Fig. 4. Wrinkle volume prior to and after 8 weeks of application. $* \mathrm{p}<0.05$.

the activation of cell surface receptors, which initiate signal transduction cascades. This, in turn, leads to a variety of molecular changes, causing a breakdown of collagen in the extracellular matrix and a shutdown of new collagen synthesis [8]. Protection of the skin by the application of antioxidants inhibited the breakdown of collagen and promoted new synthesis, which resulted in increased elasticity in the verum groups when cream application was involved.

The parameters stratum corneum moisture, wrinkle volume and epidermal thickness might all have been affected by simple hydration with the creams. Interestingly, however, the application of $\mathrm{P}$-cream only did not involve any significant improvements.

Our study revealed that the combined oral and topical application of antioxidants leads to a reduction of the wrinkle volume. Similar results were observed by other groups. Heinrich et al. [33] found a significant decrease of skin roughness after antioxidant supplementation, and Darvin et al. [17] found a significant correlation between skin roughness and lycopene concentration. The increased epidermal thickness might be induced by increased differentiation of keratinocytes caused by $\beta$-carotene application as described above. The oral supplementation or topical application of antioxidants seems to sometimes also influence the skin moisture as reported by diverse groups $[34,35]$ and revealed in this study.

The combined application of the verum cream and verum tablets did not result in increased values of skin
Lademann et al. 
parameters compared to single verum cream and single verum tablet application. A saturation effect on the stratum corneum might be a potential explanation. If the stratum corneum is already saturated by topically applied antioxidants, further antioxidants which are delivered to the skin surface via the sweat cannot be absorbed additionally $[36,37]$.

In summary, it can be stated that topical application and systemic supplementation of antioxidants have a positive effect on several skin parameters. The advantage of systemic supplementation might be that the antioxidants remain in the skin for several weeks, even after discontinuance of the systemic treatment [29]. Cream application, however, has to be continuous, because otherwise the concentration in the skin quickly degrades, i.e. within only 1 or 2 days [29]. In any event, the antioxidants utilized in relevant products should be optimized in their composition and concentration to exclude quick oxidation $[38,39]$. However, whereas topical application of cosmetic products containing antioxidants seems to not be critical, consumers of nutritional supplements should ensure that their products contain a broad mixture of antioxidants at physiological concentrations, because high concentrations of antioxidants that exceed a critical value can even act as producers of free radicals [39]. This criti- cal concentration can hardly be achieved by eating fruit and vegetables, as saturation occurs. Although a wide range of food supplements are available, providing a possible alternative to the intake of fruit and vegetables, it is difficult for the consumers to classify these products by their physiological concentrations and compositions, with comprehensive labeling and other relevant regulations being insufficient. Consequently, a healthy diet remains the best alternative for the systemic intake of antioxidants.

\section{Acknowledgements}

We would like to thank the Foundation 'Skin Physiology' of the Donor Association for German Science and Humanities for their financial support.

\section{Disclosure Statement}

The study was sponsored by Coty Lancaster SAM, Monaco, who kindly provided the creams and tablets investigated in the study. Dr. Olivier Doucet is a current employee and Prof. Leonhard Zastrow a previous employee of Coty Lancaster SAM, Monaco.

\section{References}

1 Chuong CM, Nickoloff BJ, Elias PM, Goldsmith LA, Macher E, Maderson PA, Sundberg JP, Tagami H, Plonka PM, Thestrup-Pederson K, Bernard BA, Schroder JM, Dotto P, Chang CM, Williams ML, Feingold KR, King LE, Kligman AM, Rees JL, Christophers E: What is the 'true' function of skin? Exp Dermatol 2002;11:159-187.

2 Darvin ME, Haag S, Meinke M, Zastrow L, Sterry W, Lademann J: Radical production by infrared a irradiation in human tissue. Skin Pharmacol Physiol 2010;23:40-46.

3 Wolfle U, Seelinger G, Bauer G, Meinke MC, Lademann J, Schempp CM: Reactive molecule species and antioxidative mechanisms in normal skin and skin aging. Skin Pharmacol Physiol 2014;27:316-332.

4 Zastrow L, Groth N, Klein F, Kockott D, Lademann J, Renneberg R, Ferrero L: The missing link - light-induced (280-1,600 nm) free radical formation in human skin. Skin Pharmacol Physiol 2009;22:31-44.

5 Kawaguchi Y, Tanaka H, Okada T, Konishi H, Takahashi M, Ito M, Asai J: Effect of reactive oxygen species on the elastin mRNA expression in cultured human dermal fibroblasts. Free Radic Biol Med 1997;23:162-165.
6 Monboisse JC, Poulin G, Braquet P, Randoux A, Ferradini C, Borel JP: Effect of oxy radicals on several types of collagen. Int J Tissue React 1984;6:385-390.

7 Krutmann J, Morita A, Chung JH: Sun exposure: what molecular photodermatology tells us about its good and bad sides. J Invest Dermatol 2012;132:976-984.

8 Fisher GJ: The pathophysiology of photoaging of the skin. Cutis 2005;75:5-8; discussion 8-9.

9 Murphy GM: Ultraviolet radiation and immunosuppression. Br J Dermatol 2009; 161(suppl 3):90-95.

10 Moon JS, Oh CH: Solar damage in skin tumors: quantification of elastotic material. Dermatology 2001;202:289-292.

11 Jung S, Darvin ME, Chung HS, Jung B, Lee SH, Lenz K, Chung WS, Yu RX, Patzelt A, Lee BN, Sterry W, Lademann J: Antioxidants in Asian-Korean and Caucasian skin: the influence of nutrition and stress. Skin Pharmacol Physiol 2014;27:293-302.

12 Darvin ME, Sterry W, Lademann J, Patzelt A: Alcohol consumption decreases the protection efficiency of the antioxidant network and increases the risk of sunburn in human skin. Skin Pharmacol Physiol 2013;26:45-51.
13 Lademann J, Kocher W, Yu R, Meinke MC, $\mathrm{Na}$ Lee B, Jung S, Sterry W, Darvin ME: Cutaneous carotenoids: the mirror of lifestyle? Skin Pharmacol Physiol 2014;27:201.

14 Lademann J, Schanzer S, Meinke M, Sterry W, Darvin ME: Interaction between carotenoids and free radicals in human skin. Skin Pharmacol Physiol 2011;24:238-244.

15 Lauer AC, Groth N, Haag SF, Darvin ME, Lademann J, Meinke MC: Dose-dependent vitamin $\mathrm{C}$ uptake and radical scavenging activity in human skin measured with in vivo electron paramagnetic resonance spectroscopy. Skin Pharmacol Phys 2013;26:147-154.

16 Haag SF, Taskoparan B, Darvin ME, Groth N, Lademann J, Sterry W, Meinke MC: Determination of the antioxidative capacity of the skin in vivo using resonance Raman and electron paramagnetic resonance spectroscopy. Exp Dermatol 2011;20:483-487.

17 Darvin M, Patzelt A, Gehse S, Schanzer S, Benderoth C, Sterry W, Lademann J: Cutaneous concentration of lycopene correlates significantly with the roughness of the skin. Eur J Pharm Biopharm 2008;69:943-947. 
18 Darvin ME, Gersonde I, Albrecht H, Sterry W, Lademann J: Resonance Raman spectroscopy for the detection of carotenoids in foodstuffs. Influence of the nutrition on the antioxidative potential of the skin. Laser Phys Lett 2007;4:452-456.

19 Mayne ST, Cartmel B, Scarmo S, Lin H, Leffell DJ, Welch E, Ermakov I, Bhosale P, Bernstein PS, Gellermann W: Noninvasive assessment of dermal carotenoids as a biomarker of fruit and vegetable intake. Am J Clin Nutr 2010;92: 794-800.

20 Palombo P, Fabrizi G, Ruocco V, Ruocco E, Fluhr J, Roberts R, Morganti P: Beneficial long-term effects of combined oral/topical antioxidant treatment with the carotenoids lutein and zeaxanthin on human skin: a double-blind, placebo-controlled study. Skin Pharmacol Physiol 2007;20:199-210.

21 Fitzpatrick TB: The validity and practicality of sun-reactive skin types I through VI. Arch Dermatol 1988;124:869-871.

22 Darvin ME, Richter H, Ahlberg S, Haag SF, Meinke MC, Le Quintrec D, Doucet O, Lademann J: Influence of sun exposure on the cutaneous collagen/elastin fibers and carotenoids: negative effects can be reduced by application of sunscreen. J Biophotonics 2014;7: 735-743.

23 Akhalaya MY, Maksimov GV, Rubin AB, Lademann J, Darvin ME: Molecular action mechanisms of solar infrared radiation and heat on human skin. Ageing Res Rev 2014; 16C:1-11.

24 Sahle FF, Gebre-Mariam T, Dobner B, Wohlrab J, Neubert RH: Skin diseases associated with the depletion of stratum corneum lipids and stratum corneum lipid substitution therapy. Skin Pharmacol Physiol 2015;28:42-55.
25 Arai H: Oxidative modification of lipoproteins. Subcell Biochem 2014;77:103-114.

26 Norlen L: Current understanding of skin barrier morphology. Skin Pharmacol Physiol 2013;26:213-216.

27 Darvin M, Zastrow L, Sterry W, Lademann J: Effect of supplemented and topically applied antioxidant substances on human tissue. Skin Pharmacol Phys 2006;19:238-247.

28 Pandel R, Poljsak B, Godic A, Dahmane R: Skin photoaging and the role of antioxidants in its prevention. ISRN Dermatol 2013;2013: 930164.

29 Darvin ME, Fluhr JW, Schanzer S, Richter H, Patzelt A, Meinke MC, Zastrow L, Golz K, Doucet O, Sterry W, Lademann J: Dermal carotenoid level and kinetics after topical and systemic administration of antioxidants: enrichment strategies in a controlled in vivo study. J Dermatol Sci 2011;64:53-58.

30 Wertz K, Hunziker PB, Seifert N, Riss G, Neeb M, Steiner G, Hunziker W, Goralczyk R: Betacarotene interferes with ultraviolet light Ainduced gene expression by multiple pathways. J Invest Dermatol 2005;124:428-434.

31 Lorencini M, Brohem CA, Dieamant GC, Zanchin NI, Maibach HI: Active ingredients against human epidermal aging. Ageing Res Rev 2014;15:100-115.

32 Fisher GJ, Wang ZQ, Datta SC, Varani J, Kang S, Voorhees JJ: Pathophysiology of premature skin aging induced by ultraviolet light. $\mathrm{N}$ Engl J Med 1997;337:1419-1428.
33 Heinrich U, Tronnier H, Stahl W, Bejot M, Maurette JM: Antioxidant supplements improve parameters related to skin structure in humans. Skin Pharmacol Physiol 2006;19: 224-231.

34 Fabbrocini G, Cameli N, Lorenzi S, De Padova MP, Marasca C, Izzo R, Monfrecola G: A dietary supplement to reduce side effects of oral isotretinoin therapy in acne patients. G Ital Dermatol Venereol 2014;149:441-445.

35 Gianeti MD, Mercurio DG, Campos PM: The use of green tea extract in cosmetic formulations: not only an antioxidant active ingredient. Dermatol Ther 2013;26:267-271

36 Lademann J, Caspers PJ, van der Pol A, Richter H, Patzelt A, Zastrow L, Darvin M, Sterry W, Fluhr JW: In vivo Raman spectroscopy detects increased epidermal antioxidative potential with topically applied carotenoids. Laser Phys Lett 2009;6:76-79.

37 Fluhr JW, Caspers P, van der Pol JA, Richter H, Sterry W, Lademann J, Darvin ME: Kinetics of carotenoid distribution in human skin in vivo after exogenous stress: disinfectant and wIRA-induced carotenoid depletion recovers from outside to inside. J Biomed Opt 2011;16:035002.

38 Darvin ME, Sterry W, Lademann J: Resonance Raman spectroscopy as an effective tool for the determination of antioxidative stability of cosmetic formulations. J Biophotonics 2010;3:82-88.

39 Lademann J, Patzelt A, Schanzer S, Richter H, Meinke MC, Sterry W, Zastrow L, Doucet O, Vergou T, Darvin ME: Uptake of antioxidants by natural nutrition and supplementation: pros and cons from the dermatological point of view. Skin Pharmacol Physiol 2011;24:269 273 